UCRL-JC-129779

PREPRINT

\title{
Viscoelastic Properties of Healthy Human Artery Measured in Saline Solution by AFM-Based Indentation Technique
}

\author{
A. Lundkvist, E. Lilleodden, W. Siekhaus, \\ J. Kinney, L. Pruitt, M. Balooch
}

This paper was prepared for submittal to the Materials Research Society Conference Proceedings

San Francisco, CA

April 21-28, 1995

February 9, 1998

This is a preprint of a paper intended for publication in a journal or proceedings. Since changes may be made before publication, this preprint is made available with the understanding that it will not be cited or reproduced without the permission of the author. 


\section{DISCLAIMER}

This document was prepared as an account of work sponsored by an agency of the United States Government. Neither the United States Government nor the University of California nor any of their employees, makes any warranty, express or implied, or assumes any legal liability or responsibility for the accuracy, completeness, or usefulness of any information, apparatus, product, or process disclosed, or represents that its use would not infringe privately owned rights. Reference herein to any specific commercial product, process, or service by trade name, trademark, manufacturer, or otherwise, does not necessarily constitute or imply its endorsement, recommendation, or favoring by the United States Government or the University of California. The views and opinions of authors expressed herein do not necessarily state or reflect those of the United States Government or the University of California, and shall not be used for advertising or product endorsement purposes. 


\title{
Viscoelastic Properties of Healthy Human Artery Measured in Saline Solution by AFM- Based Indentation Technique
}

\author{
A. Lundkvist**, E. Lilleodden*, W. Siekhaus*, J. Kinney*, L. Pruitt** and M. Balooch* \\ * Lawrence Livermore National Laboratory, Livermore CA 94550, balooch1 @ llnl.gov \\ ** University of California, Berkeley CA 94720
}

\begin{abstract}
Using an Atomic Force Microscope with an attachment for indentation, we have measured local, in vitro mechanical properties of healthy femoral artery tissue held in saline solution. The elastic modulus $(34.3 \mathrm{kPa})$ and viscoelastic response $\left(\tau_{\varepsilon}=16.9 \mathrm{~s}\right.$ and $\left.\tau_{\sigma}=29.3 \mathrm{~s}\right)$ of the unstretched, intimal vessel wall have been determined using Sneddon theory and a three element model (standard linear solid) for viscoelastic materials. The procedures necessary to employ the indenting attachment to detect elastic moduli in the $\mathrm{kPa}$ range in liquid are described.
\end{abstract}

\section{INTRODUCTION}

Coronary artery disease or atherosclerosis is the leading cause of death in the United States [1]. Percutaneous Transluminal Coronary Angioplasty (PTCA) is the most common treatment for patients suffering from atherosclerosis. Although PTCA yields a greater than $90 \%$ immediate success rate, the 30-40\% restenosis rate, or re-narrowing of the coronary arteries, hinders complete success [2]. A significant portion of this restenosis rate is due to geometric remodeling of the diseased artery wall incurred during balloon inflation (e.g. medial stretching [2], plaque dissection [3] and plaque compression [2,3]). If the plaque contains a significant amount of calcium deposits, preferential regions of high stress conducive to stretching or dissection may form during balloon inflation. Eighty percent of patients recommended for PTCA exhibit calcium deposits in the plaque [4]. Hence, there is particular clinical interest in understanding the local material properties and mechanical behavior of calcified atherosclerotic deposits and healthy arterial wall.

The present work describes the technique of using the AFM-based nanoindenter to determine the mechanical properties of soft tissues held in saline solution. The static elastic modulus and viscoelastic constants of the intimal surface of a healthy human femoral artery are reported. These results will be used as a base for further studies on atherosclerotic coronary tissues.

\section{EXPERIMENTAL TECHNIQUE AND RESULTS}

The Atomic Force Microscope (small stage Nanoscope III, Digital Instruments, Santa Barbara, CA) has been modified by replacing the conventional head assembly with a transducerindenter assembly called a Micromechanical Testing Instrument (Hysitron Inc., Minneapolis, MN). Like its conventional counterpart, the instrument can image the topography of specimens by tracing the superficial contours of the sample with nano-Newton loads. In addition, the device is a force-generating and depth-sensing instrument (Nano-indenter) capable of generating loaddisplacement curves at specific locations in ambient and, with the corrections described here, liquid environments. The minimum load applied is less than $1 \mu \mathrm{N}$ and the maximum displacement measured is $35 \mu \mathrm{m}$. Indenters of varying materials (diamond, tungsten carbide, aluminum); shapes (Berkovich, spherical, flat cylindrical punch) and a range of diameters (.17 to $2.0 \mathrm{~mm}$ ) have been used for indentation of healthy human arteries.

For the experiments reported here, healthy femoral arteries supplied by the National Disease Research Interchange (NDRI) were scanned by intravascular ultrasound (Boston Scientific, Sunnyvale, CA) to ascertain that no plaque existed. The vessel was cut longitudinally, sectioned in $5 \mathrm{~mm} \times 5 \mathrm{~mm}$ regions and placed unstretched in a $.9 \%$ saline bath on the AFM stage. 
The basic components of the Micromechanical Testing Instrument are shown in Figure 1. The force recorded and displayed by the instrument is defined as,

$F_{\text {display }}=A \varepsilon_{0} \frac{V^{2}}{d_{0}^{2}}$

where $\mathrm{A}$ is the plate area, $\mathrm{V}$ is the voltage applied between the drive plate and pickup electrode, $\varepsilon_{0}$ is the dielectric constant and $\mathrm{d}_{0}$ is the spacing between the pickup electrode and drive plate when no weight (such as the indenter) is attached and no voltage is applied. The vender specifies $\mathrm{d}_{0}$ as $120 \mu \mathrm{m}$. In many material science applications, equation (1) adequately represents the actual force applied to the material under investigation.

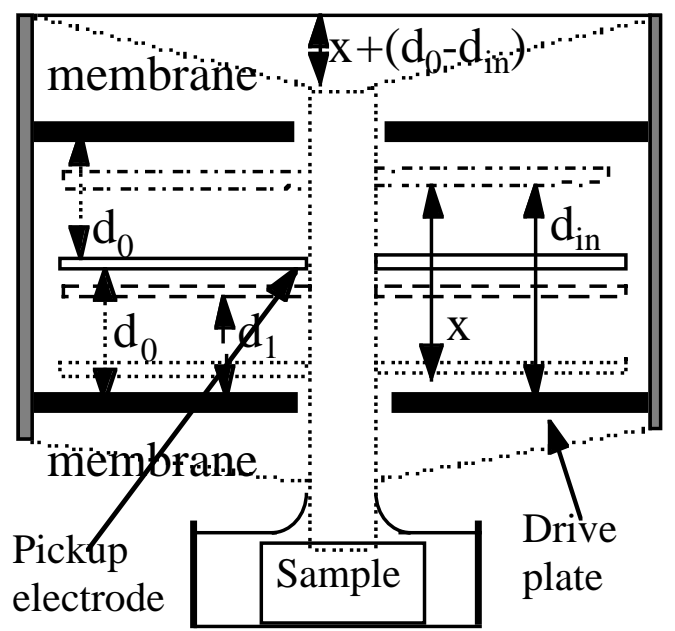

Figure 1. Schematic of Micromechanical Testing Instrument with parameters needed to determine the actual force applied to soft materials in saline solution. The combination of pickup electrode and drive plates is used to both generate a force, $\mathrm{F}_{\text {display }}$, and to measure displacement, $\mathrm{x}$.

For soft materials, however, the displacements could be large even for small applied voltages. In this case, the change in the plate spacing deviates substantially from that described by equation 1, and the force displayed does not equal the force actually applied to the sample. Additionally, the stiffness of the membrane, the weight of the indenter itself and the force exerted on the indenter's shaft as a result of surface tension should be included to accurately describe the applied force in liquid. The actual force applied to the sample is

$F_{a}=F_{\text {display }}\left[\frac{d_{0}}{d_{\text {in }}-x}\right]^{2}-K_{s}\left(x+d_{0}-d_{\text {in }}\right)+F_{\text {s.t. }}+M g$

where $\mathrm{x}$ is the displacement of the pickup electrode from its initial position $\mathrm{d}_{\mathrm{in}}, \mathrm{K}_{\mathrm{s}}$ is the spring constant of the membrane (ignoring possible nonlinearity), $\mathrm{Mg}$ is the weight of the indenter and $\mathrm{F}_{\text {s.t. }}$ is the force due to surface tension. When a preload is applied to the sample, the force due to the initial displacement is 
$\operatorname{Preload}=K_{S}\left(d_{\text {in }}-d_{1}^{l i q}\right)$

In the absence of an initial preload, the initial spacing, $\mathrm{d}_{\mathrm{in}}$, is replaced by

$$
\mathbf{d}_{1}^{\operatorname{liq}}=\mathbf{d}_{\mathbf{1}}^{\text {air }}-\frac{\mathbf{F}_{\text {s.t. }}}{\mathbf{K}_{\mathbf{s}}}
$$

where $d_{1}^{\text {air }}$ is the spacing between the pickup electrode and drive plate in air due to the weight of the attached indenter (Figure 1 ). $\mathrm{K}_{\mathrm{S}}$ and $\mathrm{d}_{1}$ air are determined by making a best fit to displayed force versus distance curves of several calibration runs done in air without a load applied to the sample. The results are shown in Figure $2 \mathrm{a}$ along with the deviation of experimental points from the optimum fit. The experiments were repeated in liquid with no load applied to the sample to obtain $\mathrm{F}_{\text {s.t. }}$. The result of the curve fit and its deviation from data points in liquid is shown in Figure $2 b$.

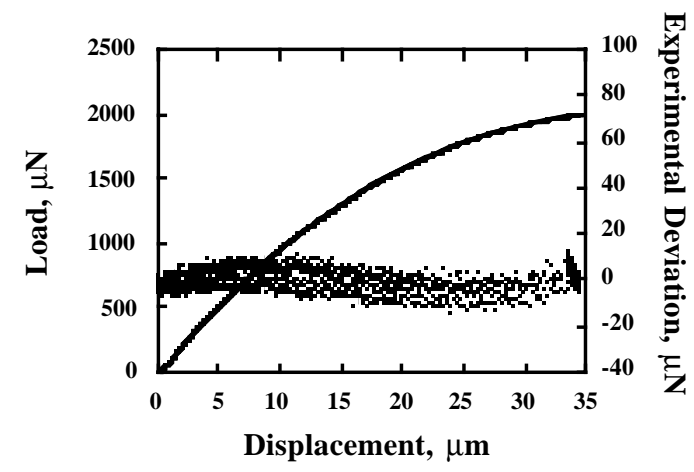

$2 \mathrm{a}$

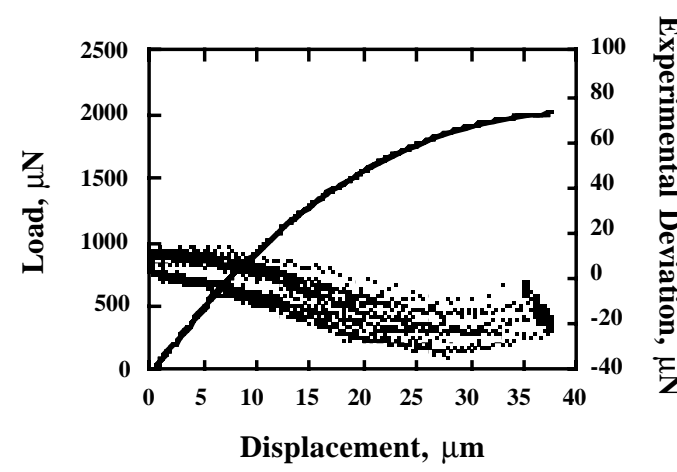

$2 b$

Figure 2. Displayed force vs. displacement with no load applied to the sample, and the deviation of experimental results from the optimum fit to force vs. displacement: a) in air b) in saline solution.

Since healthy human arteries are known to have high compliance, this study used a flat circular punch consisting of a thin aluminum disk $2 \mathrm{~mm}$ in diameter, attached to a stem of $.5 \mathrm{~mm}$ diameter (to minimize surface tension forces) held by the mechanical testing instrument. The "sine wave" appearance of the deviation of experimental results from the optimum fit to curves of force vs. displacement evident in both air and liquid calibration runs in Figure 2 can be eliminated when a nonlinear third-power term is added, as suggested by Timoshenko [5], to describe the force vs. displacement of the membrane. The load accuracy of the measurements is $\pm 10 \mu \mathrm{N}$ in air and $\pm 20 \mu \mathrm{N}$ in saline solution, and by almost a factor of two better when a nonlinear spring is considered.

The data were analyzed using a simple three element model (standard linear solid [6])--a spring $\left(\mu_{0}\right)$ placed in parallel with a Maxwell spring $\left(\mu_{1}\right)$-damper $\left(\eta_{1}\right)$ system. The behavior of this model is characterized by three parameters:

$$
\tau_{\varepsilon}=\frac{\eta_{1}}{\mu_{1}}, \quad \tau_{\sigma}=\frac{\eta_{1}}{\mu_{0}}\left(1+\frac{\mu_{\mathbf{0}}}{\mu_{1}}\right) \quad \text { and } \quad \mathbf{E}_{\mathbf{R}}=\frac{\mu_{\mathbf{0}}}{2 \mathrm{r}}
$$


where $\tau_{\varepsilon}$ is the relaxation time for constant strain, $\tau_{\sigma}$ is the relaxation time for constant stress, $r$ is the indenter radius and $E_{R}$ is the relaxed elastic modulus of the system as time approaches infinity, based on contact stiffness and Sneddon indentation theory [7,8]. The creep response [6], c(t), of this system to a constant force of magnitude unity, $u(t)$, is described as

$$
\mathbf{c}(\mathbf{t})=\frac{1}{\mu_{0}}\left[\mathbf{1}-\left(\mathbf{1}-\frac{\tau_{\varepsilon}}{\tau_{\sigma}}\right) \mathbf{e}^{-\mathbf{t} / \tau_{\sigma}}\right] \mathbf{u}(\mathbf{t})
$$

The actual force and displacement vs. time for a healthy artery are shown in Figure 3 . The instrument was programmed to generate a trapezoidal "display-force" vs. time. Applying the corrections described in equations (2) - (4) provided the time-dependent actual applied force shown in Figure 3. A second order polynomial was fit to the loading portion of the actual applied force vs. time curve and this fitted analytic function, $F(t)$, was integrated using the Boltzmann superposition principle for creep response given an arbitrary load profile [6]. This results in an analytic displacement function, $\mathrm{X}(\mathrm{t})$, containing three undetermined model parameters $\mu_{0}, \tau_{\varepsilon}$ and $\tau_{0}$

$$
\mathbf{X}(\mathbf{t})=\frac{1}{\mu_{0}}\left[\left.\mathbf{F}(\mathbf{t})\right|_{0} ^{\mathbf{t}}-\left(\mathbf{1}-\frac{\tau_{\varepsilon}}{\tau_{\sigma}}\right) \mathbf{e}^{-\mathbf{t} / \tau_{\sigma}} \int_{0}^{\mathbf{t}} \mathbf{e}^{+\tau / \tau_{\sigma}} \frac{\mathbf{d F}(\tau)}{\mathbf{d} \tau} \mathbf{d} \tau\right]
$$

This function was then fit to the measured displacement during the loading-only portion of the displacement vs. time data to determine the model parameters. These parameters were then used in the Boltzmann integral on the actual applied load curve $\mathrm{F}(\mathrm{t})$ to predict the displacement vs. time data, as plotted in figure 3.

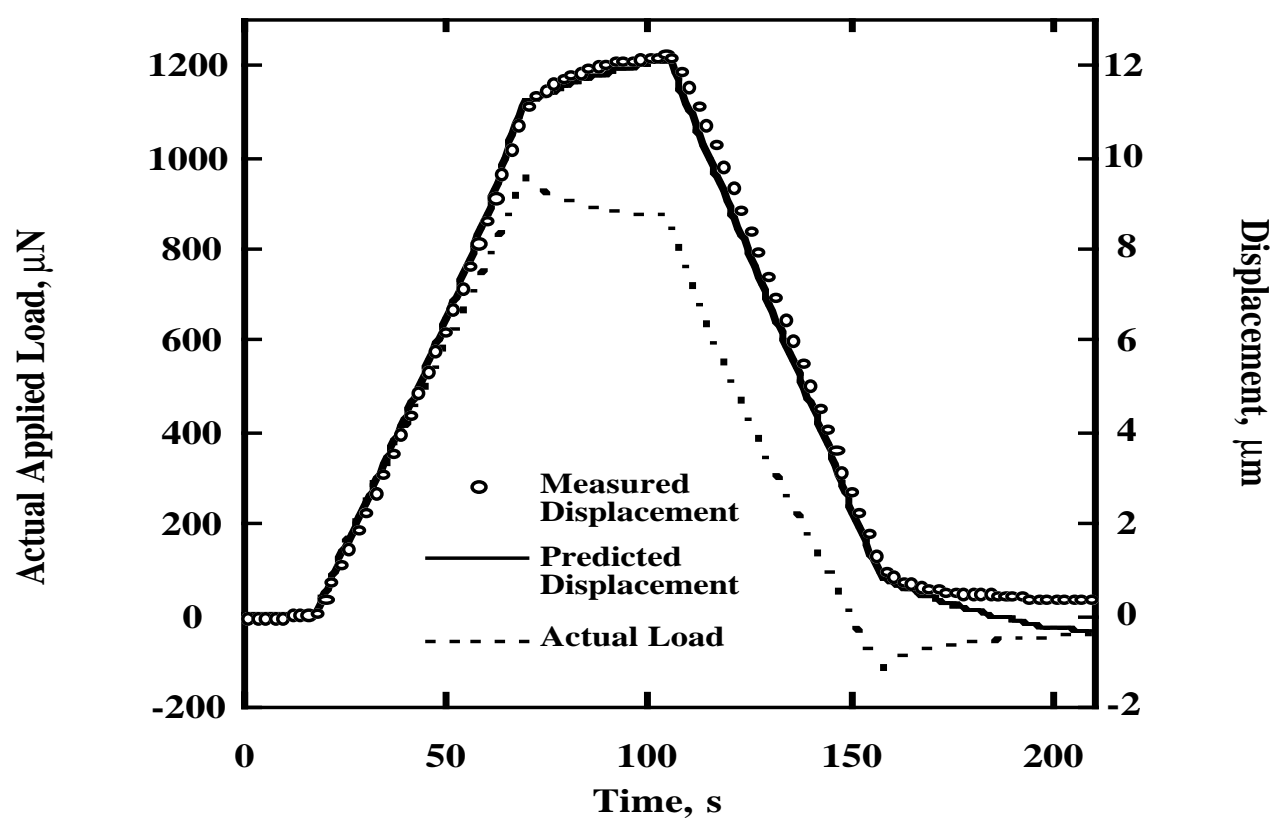

Figure 3. The actual force applied and measured displacement as a function of time for a healthy, femoral artery wall using a $2 \mathrm{~mm}$ diameter, aluminum, flat punch. The Boltzmann superposition 
principle was used to predict the displacement vs. time based on the Kelvin model parameters and the time-dependent loading curve.

Table I compares the results of this study with previous indentation studies. Although the elastic modulus values reported by Gow et al. $[9,10]$ were obtained with indenters smaller in diameter than used here, information about the viscoelastic response is not provided. The technique used by Lee et al. [11] used a $7 \mathrm{~mm}$ diameter indenter, and hence the results represent an average over an area more than 10 times larger than the area used in this study. In addition to providing local measurements of the elastic modulus of healthy, femoral artery (intimal) wall, to the best of the authors' knowledge, this investigation represents the first in vitro, localized assessment of the viscoelastic response of healthy inner arterial wall. 


\section{Table I: Comparison of Previous Indentation Studies with this Study (*)}

$\begin{array}{llc}\text { Aortic Intimal } & \text { Non-Fibrous Aortic } & * \text { Healthy Femoral } \\ \text { Surface }[9,10] & \text { Plaque Caps [11] } & \text { Intimal Wall }\end{array}$

\begin{tabular}{|c|c|c|c|c|}
\hline & $\mathrm{s}(\mathrm{kPa})$ & & & \\
\hline$\tau_{\varepsilon}$ & $(\mathrm{sec})$ & --- & --- & 16.9 \\
\hline$\tau_{\sigma}$ & $(\mathrm{sec})$ & --- & --- & 29.3 \\
\hline
\end{tabular}

\section{SUMMARY AND CONCLUSIONS}

The add-on transducer to the standard AFM enhanced the capability of the instrument to measure local mechanical properties in addition to topographic imaging. To further increase its capability for use on soft tissues held in aqueous solution one also needs to consider the forces applied to the indenter, such as weight and surface tension, that are usually negligible for most materials used in engineering applications. By considering these forces, the viscoelastic properties of an unstretched healthy artery wall in saline solution have been measured. To the authors' knowledge, there is no previous 3 parameter-based model of the mechanical response of the intimal layer of the artery wall.

The instrumentation described here is being used with smaller indenters $(.175 \mathrm{~mm}$ diameter) to measure the static mechanical and viscoelastic response of healthy and diseased arteries over a wide range of frequencies. These investigations will provide a sound engineering basis for future balloon angioplasty studies, and will help to improve the design of other clinical devices used to treat patients with coronary artery disease.

\section{ACKNOWLEDGMENTS}

This work was supported by the U.S. Department of Energy, through the LDRD program at Lawrence Livermore National Laboratory under contract No. W-7405-ENG-48.

We want to thank Dr. W. Gerberich, U. of Minnesota, Dept. of Mechanical Engineering and Material Science; Dr. P. Yock, Stanford University Medical Center for Research in Interventional Cardiology; Greg Hyde, Guidant Corp., Advanced Cardiovascular Systems; and Dr. Wayne Bonin, Hysitron Inc. for their contributions to the scientific and technical substance of this paper. 


\section{REFERENCES}

1. Heart and Stroke Facts: 1994 Statistical Supplement, American Heart Association.

2. R. Virmani, A. Farb and A.P. Burke, American Heart Journal 127: 163-179 (1994).

3. B.F. Waller, C.M. Orr, C.A. Pinkerton, J. Van Tassel, T. Peters and J.D. Slack, Journal of the American College of Cardiology 20 (3): 701-706 (1992).

4. L.A. Fitzpatrick, A. Severson, W.D. Edwards and R.T. Ingram, Journal of Clinical Investigation 94: 1597-1604 (1994).

5. S. P. Timoshenko and J. N. Goodier. Theory of Elasticity, 3rd edition. (McGraw Hill Book Company, New York, 1970).

6. Y.C. Fung, Biomechanics, 2nd ed. (Springer-Verlag New York, Inc., New York, 1993), pp.41-46.

7. I.N. Sneddon, International Journal of Engineering Science 3: 47 (1965).

8. G.M Pharr, W.C. Oliver and F.R. Brotzen, Journal of Materials Research 7 (3): 613617 (1992).

9. B.S. Gow and R.N. Vaishnav, Journal of Applied Physiology 38 (2): 344-50 (1975).

10. B.S. Gow, W.D. Castle and M.J. Legg, Journal of Biomechanics 16 (6): 451-458 (1983).

11. R.T. Lee, G. Richardson, H.M. Loree, A.J. Grodzinsky, S.A. Gharib, F.J. Schoen and N. Pandian, Arteriosclerosis and Thrombosis 12 (1): 1-5 (1992). 


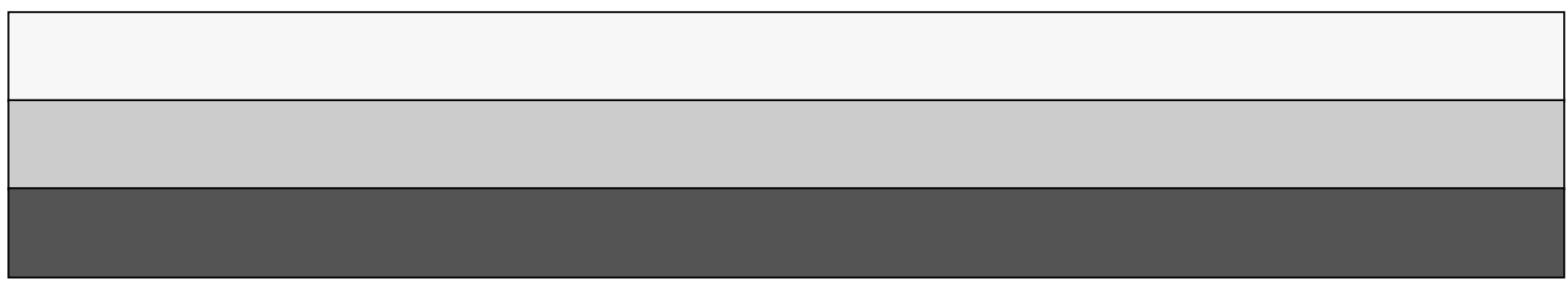

